\title{
Thermal tolerance trade-offs associated with the right arm of chromosome 3 and marked by the hsr-omega gene in Drosophila melanogaster
}

\author{
AR Anderson ${ }^{1}$, JE Collinge ${ }^{1}$, AA Hoffmann ${ }^{2}$, M Kellett $^{1}$ and SW McKechnie ${ }^{1}$ \\ ${ }^{1}$ Centre for Environmental Stress and Adaptation Research, School of Biological Sciences, Monash University, Victoria 3800, Australia; \\ ${ }^{2}$ Centre for Environmental Stress and Adaptation Research, La Trobe University, Bundoora, Victoria 3083, Australia
}

\begin{abstract}
Drosophila melanogaster occurs in diverse climatic regions and shows opposing clinal changes in resistance to heat and resistance to cold along a $3000 \mathrm{~km}$ latitudinal transect on the eastern coast of Australia. We report here on variation at a polymorphic $8 \mathrm{bp}$-indel site in the heat shock hsr-omega gene that maps to the right arm of chromosome 3 . The frequency of the genetic element marked by the $L$ form of the gene was strongly and positively associated with latitude along this transect, and latitudinal differences in $L$ frequency were robustly associated with latitudinal differences in maximum temperature for the hottest month. On a genetic background mixed for genes from each end of the cline a set of 10 lines was derived, five of which were fixed for the $\mathrm{L}$ marker, the absence of $\ln (3 R) P$ and $12 \mathrm{~kb}$ of repeats at a
\end{abstract}

second polymorphic site at the $3^{\prime}$ end of $h s r-o m e g a$, and five that were fixed for the $S$ marker, $\ln (3 R) P$ and $15 \mathrm{~kb}$ of $h s r-$ omega repeats. For two different measures of heat tolerance $S$ lines outperformed $L$ lines, and for two different measures of cold tolerance $L$ lines outperformed $S$ lines. These data suggest that an element on the right arm of chromosome 3 , possibly $\ln (3 R) P$, confers heat resistance but carries the trade-off of also conferring susceptibility to cold. This element occurs at high frequency near the equator. The alternate element on the other hand, at high frequency at temperate latitudes, confers cold resistance at the cost of heat susceptibility.

Heredity (2003) 90, 195-202. doi:10.1038/sj.hdy.6800220

Keywords: heat and cold tolerance; tradeoff; latitudinal variation; Drosophila melanogaster, hsr-omega; polymorphism

\section{Introduction}

Research in Drosophila is providing a focus for understanding the physiological and genetic basis of thermal tolerance variation in ectotherms (Huey and Kingsolver, 1993; Duncker et al, 1995; Krebs and Loeschcke, 1995; Guerra et al, 1997; Ohtsu et al, 1998). Significant variation in resistance to temperature extremes are known among several groups of closely related Drosophila species and these are likely to be adaptive since they are related to the climatic zones where the species are found (Kimura, 1988; Jenkins and Hoffmann, 1994; Gibert et al, 2001). While thermal tolerance is an important factor limiting the distribution of species, some species such as the cosmopolitan Drosophila melanogaster successfully survive and reproduce over a broad range of climatic zones that cover a wide spectrum of thermal extremes. Heritable strain variation and regional variation in thermal tolerance have been well documented for this species (Parsons, 1977; Stalker, 1980); however, only recently has a firm basis been established for believing that an adaptive cause underlies this variation. Opposing latitudinal clines in resistance to both heat and cold temperature extremes occurred along a north-south transect of samples from the eastern coast of Australia

Correspondence: SW McKechnie, School of Biological Sciences, Monash University, Victoria 3800, Australia.

E-mail : s.mckechnie@sci.monash.edu.au

Received 29 May 2002; accepted 26 September 2002
(Hoffmann et al, 2002). In samples not confounded by variation in altitude, knockdown time when exposed to heat shock increased towards the tropics whereas recovery time following cold shock decreased towards temperate high latitude regions, as might be predicted under an adaptive scenario.

This Australian eastern coast transect for D. melanogaster has recently been shown to vary in a clinal fashion for a number of different quantitative traits, in addition to the heat and cold tolerance clines. Traits that change with latitude include body size (Partridge et al, 1999), egg size (Azevedo et al, 1996) and life-history traits (Mitrovski and Hoffmann, 2001). Clinal variation also occurs for numerous genetic markers, including the frequency of four common cosmopolitan inversions (Knibb et al, 1981), and allele frequencies of numerous polymorphic markers (Oakeshott et al, 1984) including five microsatellite markers (Gockel et al, 2001). Many of these variations are also 'generic', occurring in a latitudinally consistent manner on other continents (Knibb, 1982; Mettler et al, 1977; Inoue et al, 1994), and in related species (Oakeshott et al, 1984). A major question of interest is the relation between the quantitative traits and the genetic markers, and the extent to which we can understand the genetic and physiological/selective basis of the differential adaptation to climate along these latitudinal clines.

Towards this end, we have recently focused on thermal tolerance variation and its relation to polymorphic candidate gene variation (McColl et al, 1996). In 
particular, strong clinal variation in allele frequency of a polymorphic heat shock gene, hsr-omega, parallels the thermal tolerance clines down the Australian eastern coast (McColl and McKechnie, 1999). Further, in laboratory studies heat-tolerance variation has been associated with molecular variation in hsr-omega and with variation in two other heat shock genes, hsp70 and hsp68, all of which map to the right arm of chromosome 3 (Figure 1) (McColl et al, 1996; Feder and Hofmann, 1999). The right arm of chromosome 3 harbours the large cosmopolitan inversion $\operatorname{In}(3 R) P$ that also varies latitudinally (Knibb et al, 1981). Both hsr-omega and hsp68 map within the bounds of $\operatorname{In}(3 R) P$. This linkage and latitudinal association of the heat-shock-protein markers and an inversion hints at a possible causal role of chromosome 3R in clinal thermal-tolerance variation. Intriguingly, heat shock genes may also play a role in recovery from cold stress (Guy et al, 1986; Chen et al, 1987; Burton et al, 1988), and hsr-omega in particular has been implicated in expression changes following cold exposure (Singh and Lakhotia, 1984; Lakhotia and Singh, 1985). A major effect of chromosome 3 on population variation in cold tolerance has been previously indicated (Tucic, 1979).

In this report, we use polymorphic variation in the hsromega gene as a marker for variation that occurs on the right arm of chromosome 3 and we ask about the relation between variation in this marker and both heat and cold tolerance variation. We chose two different ways of testing tolerance to these extremes, to see if the associations are of general significance. One of these

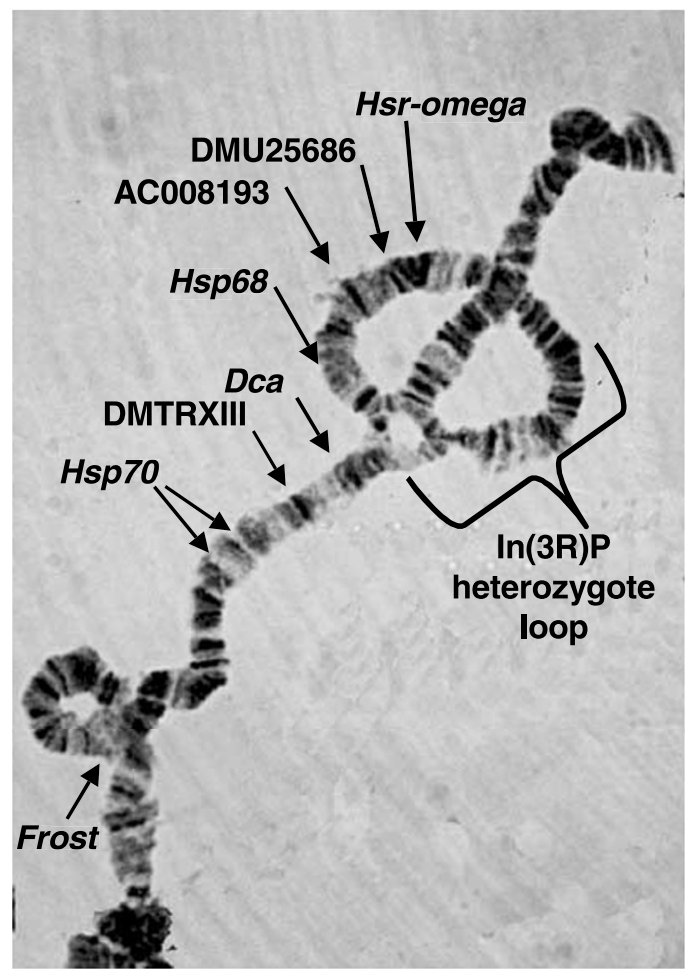

Figure 1 Drosophila melanogaster right arm of chromosome three. Depicted are cytological locations of $\operatorname{In}(3 R) P$ (89C2-C3 - 96A18), hsr omega (93D), Dca (88D), Frost (85E2), hsp63 (95D), hsp70a,b (87A,C), microsatellites DMU25686 (93F), AC008193 (94D) and DMTRX3 (88B3) on a polytene chromosome spread of the right arm of chromosome 3 from an individual heterozygous for $\operatorname{In}(3 R) P$. heat-tolerance tests and one of the cold-tolerance tests are identical to those used to detect clinal variation along the eastern Australian transect (Hoffmann et al, 2002). Our data strongly suggest that the right arm of chromosome 3 is involved with genetic adaptation to both heat and cold stress and that fitness trade-offs are involved; heat resistance comes at the cost of cold susceptibility, and the cost of being cold tolerant is susceptibility to heat.

\section{Materials and methods}

\section{Drosophila lines}

A total of 160 D. melanogaster isofemale lines were collected from December 1999 to February 2000 along the east-coast of Australia. A minimum of four and maximum of 15 isofemale lines were collected from 19 sites and were reared in vials on treacle medium at $18^{\circ} \mathrm{C}$ with constant light in the laboratory. Two isofemale lines from the east-coast collection were used for the hybrid study. Line 11T was fixed for the $h s r$-omega ${ }^{L}$ allele (L) and was collected from Huon, Tasmania. Line13Q was fixed for the hsr-omegas (S) allele and was collected from Weipa, in far northern Queensland. To produce hybrid lines 25 virgin females from each line were mated en masse with 25 males from the other line. Progeny from the two crosses were mixed at eclosion and allowed to interbreed en masse for five discrete generations in a large population cage at $25^{\circ} \mathrm{C}$. More than 100 single-pair matings were set up from this cage and parents were genotyped for $h s r$-omega $a^{L / S}$. A subset of 15 of these lines were selected for testing according to genotype; five lines fixed for the $\mathrm{L}$ allele, five for $\mathrm{S}$ and five $\mathrm{H}$ lines (50\% for each allele). Hybrid lines were reared on treacle medium at $25^{\circ} \mathrm{C}$ with constant light.

\section{Genotyping - In(3R)P cytology}

Males from the derived 'hybrid' lines that were fixed for $L$ and $S$ were crossed to a line known to have the standard arrangement of chromosome 3R (Celera, virgin females) and larval progeny were genotyped for the heterozygous loop. Polytene squashes were carried out as described by Yoon et al (1973). Briefly, salivary glands were dissected from third instar larvae in Becker Ringer's solution and placed in $45 \%$ acetic acid for $10 \mathrm{~s}$, then in $1 \mathrm{M} \mathrm{HCl}$ for $30 \mathrm{~s}$, before staining in lacto-acetoorcein for $40 \mathrm{~min}$. After staining, glands were transferred to lactoacetic acid to visualize the glands. The preparation was covered with a cover slip and squashed and examined with $\times 100$ microscopy. The third chromosome was recognized by landmark banding patterns and the presence/absence of an inversion heterozygous loop was recorded.

\section{Genotyping - hsr-omega}

Single fly DNA extraction was performed using a modified proteinase K method (Saiki et al, 1987). Single flies were ground in $100 \mu \mathrm{l} 10 \mathrm{mM}$ Tris- $\mathrm{HCl} \mathrm{pH} 8.2,1 \mathrm{mM}$ EDTA, $25 \mathrm{mM} \mathrm{NaCl}$ and $200 \mu \mathrm{g} / \mathrm{ml}$ Proteinase K. Homogenates were left at room temperature for 25$30 \mathrm{~min}$ and then heated to $95^{\circ} \mathrm{C}$ for $2 \mathrm{~min}$ to inactivate proteinase K. DNA $(10 \mu \mathrm{l})$ was used as template in the PCR amplification ( $25 \mu \mathrm{l}$ final volume). Two primers, $5^{\prime}$ GCA GTC TGA GGC AGT TAT CC-3' and 5'-CAA TCT 
TTC AAA ATC CGC AG-3', were designed using the EMBL database (DM18307) to give fragments of 86 and $94 \mathrm{bp}$ for the hsr-omegas and the hsr-omega ${ }^{L}$ alleles, respectively. The PCR products were electrophoresed through horizontal $10 \%$ thin-layer polyacrylamide gels or for large-scale genotyping, through 3.5\% agarose-1000. For Southern blots, DNA extractions were carried out on 25 adults that were glass-pestle ground using a standard proteinase $\mathrm{K} /$ phenol/chloroform protocol. The DNA $(\sim 3.5 \mu \mathrm{g} / \mu \mathrm{l})$ was digested with PstI and HindIII (that cut outside but not within the tandem repeat segment) overnight at $37^{\circ} \mathrm{C}$. A probe was produced from wildtype genomic DNA (RNase treated) using primers (5'-CGA AAA GGC TTA TCC TCT TGG, 5'-ATA GTG ATT GGG GTA ATC GGG) that bind to each end of the hsr-omega $280 \mathrm{bp}$ tandem repeat unit. PCR amplification entailed 36 cycles of $94^{\circ} \mathrm{C}(5 \mathrm{~min}), 47^{\circ} \mathrm{C}(30 \mathrm{~s})$ and $72^{\circ} \mathrm{C}(10 \mathrm{~s})$. The product was purified using Wizard PCR Preps (Promega) and used in conjunction with a GIGAprime DNA Labelling Kit (Geneworks) to make the ${ }^{32}$ P-labelled probe for hybridization.

\section{Thermal tolerance}

Thermal tolerance has been variously measured using mortality assays, knockdown assays or recovery assays (Parsons, 1977; McColl et al, 1996; Gibert et al, 2001). Often, for any one type of stress (eg heat) different physiological and genetic mechanisms have been implicated (Hoffmann et al, 1997), at least in part. In order to maximize our chances of detecting effects of mechanisms that may be relevant to natural populations, we have used two different knockdown assays to measure heat resistance, and both a mortality assay and recovery assay for cold tolerance.

\section{Heat tolerance}

Two measures of heat tolerance were applied. First, the set of 15 hybrid lines and their two parental isofemale lines were tested for heat knockdown as single flies (females) in small, capped, vials $(5 \mathrm{~mm}$ by $20 \mathrm{~mm}$ ) emerged in a circulating waterbath tank at $39^{\circ} \mathrm{C}$ with a clear glass side for scoring. Adults were reared at $25^{\circ} \mathrm{C}$ and aged in fresh-medium bottles for 3-4 days prior to testing. Knockdown time was scored in batches of six lines of 20 flies per line (10 nonhardened and 10 hardened). For hardening, flies were placed in a $37^{\circ} \mathrm{C}$ incubator for $1 \mathrm{~h}$ and aged for a further $6 \mathrm{~h}$ at $25^{\circ} \mathrm{C}$ before being tested. Two lines (one parental and one $\mathrm{H}$ line; both nonhardened) were included in all batches with the four test lines as internal standard to control for variation between batches. For analyses individual knockdown times were divided by the mean knockdown times of all control flies from the batch, and for ANOVA the data were square-root transformed.

Second, heat-knockdown was carried out in a large knockdown tube, $80 \mathrm{~cm}$ long, with an internal diameter of $9.5 \mathrm{~cm}$. Adults were reared and hardened as for the small-vial heat-knockdown test. The tube was surrounded by a water jacket attached to a Ratek circulating bath set at $39^{\circ} \mathrm{C}$. The temperature within the tube was $38.5-39^{\circ} \mathrm{C}$. Each knockdown run involved a comparison of four lines (150 flies each; sexes mixed): three test and one control line. Lines in the same knockdown run were distinguished by marking them with different coloured (pink, orange, yellow, no dust) fluorescent dusts (Hele- con, Hackettstown, NJ, USA). Flies were placed in empty vials with about $3.5 \mathrm{mg}$ of fluorescent dust and allowed to recover from dusting for $24 \mathrm{~h}$ in fresh bottles, before testing. Flies were not anaesthetized at any time. After collection from heat knockdown in a chronological series of vials, flies were frozen and later sorted and counted according to dust colour under a dissecting microscope.

Tolerance for each line was recorded as average time taken for individual flies to knockdown (as a ratio of the control line) based on 150 flies in each of three replicate runs.

\section{Cold tolerance}

This was measured using a chill coma assay (Gibert et al, 2001) and a mortality assay (Hoffmann and Parsons, 1993). Briefly, for the chill coma assay single adult flies were exposed to $0^{\circ} \mathrm{C}$ for $16 \mathrm{~h}$ in glass vials. Flies were then transferred to $25^{\circ} \mathrm{C}$ and recovery time measured every minute. A fly was considered as having recovered when able to stand on its legs. For the mortality assay, cold tolerance was determined by exposing vials of 20 females to $-2^{\circ} \mathrm{C}$ for $2 \mathrm{~h}$ and survivors were scored after $24 \mathrm{~h}$. Tests on the hybrid-line set involved preculture at $25^{\circ} \mathrm{C}$ in constant light. Number of survivors were analysed by nested ANOVA.

\section{Statistics}

Climatic data, downloaded from the Australian Bureau of Meteorology website (www.bom.gov.au), were obtained from neighbouring weather stations closest to the collection site. The climatic variables were: average daily maximum temperature $\left({ }^{\circ} \mathrm{C}\right)$ for the hottest calendar month; average daily minimum temperature $\left({ }^{\circ} \mathrm{C}\right)$ for the coldest calendar month; mean monthly rainfall for the wettest month; mean monthly rainfall for the driest month; mean humidity levels at 9 am for the most humid month; and mean humidity levels at 9 am for the driest month. Temperature, rainfall and humidity averages were based on all the available data for the particular weather station usually exceeding 100 years. Associations between latitude were initially tested using linear regression (SPSS 7.0 for Windows). To test for associations between allele frequency, latitude and climatic variables, Mantel matrix comparison tests (and partial mantel tests using matrices of residuals based on standardized differences) were carried out (Fortin and Gurevitch, 1993). These tests minimize the complications of spatial autocorrelation (nonindependence of data points). Matrix comparisons utilized GENEPOP, version 3.1 (http://www.cefe.cnts.mop.ft/ Raymond and Rousset, 1995).

\section{Results}

The hsr-omega association with heat tolerance in laboratory studies and with latitude, previously reported (McColl et al, 1996), is for an $\mathrm{A} / \mathrm{T}$ variation at the $5^{\prime}$ end of the gene that is detected by denaturing gradient gel electrophoresis (DGGE; Figure 2a, b). Since scoring large samples by DGGE is time consuming, and since linkage disequilibrium across many polymorphic sites has been indicated for this region (McKechnie et al, 1998), to expedite scoring of allelic variation, we developed a simple gel technique for an adjacent polymorphic site, 
a

Hsr-omega

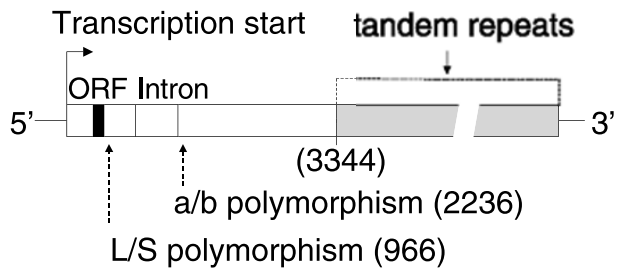

b

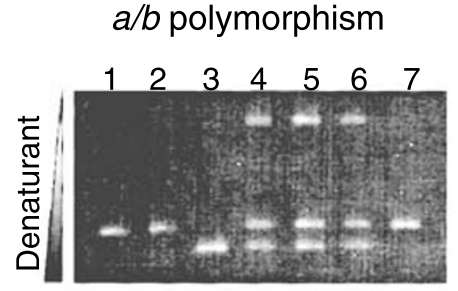

c

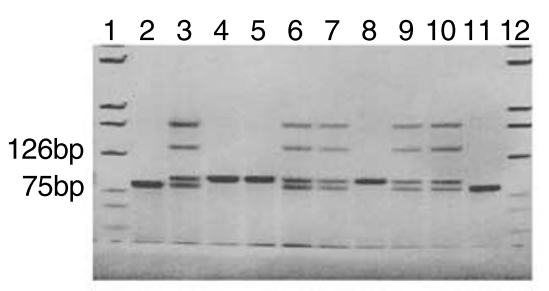

d

\section{Tandem repeats}

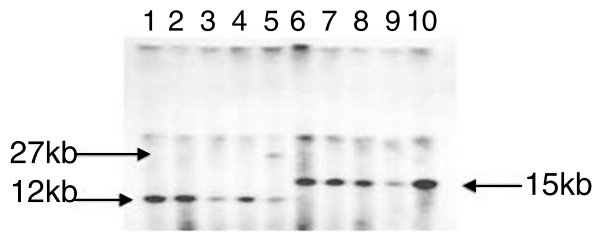

Figure 2 (a) hsr-omega structure and polymorphic sites. ORF marks a potential open reading frame. (b) Separation of $h s r$-omega and $h s r-$ omega $a^{b}$ alleles by denaturing gradient gel electrophoresis. Lanes 1, 2 and 7: hsr-omega $a^{a}$ homozygotes, lane 3: hsr-omega $a^{b}$ homozygotes and lanes 4-6: hsr-omega a/b heterozygotes. Top bands in lanes 4-6 are heteroduplex bands. (c) Separation of hsr-omega ${ }^{L}$ and $h s r$-omegas alleles by horizontal thin-layer polyacrylamide gels. Lanes 1, 12: pGem DNA marker (Promega); lanes 2, 11: hsr-omega ${ }^{S}$ homozygotes; lanes 3, 6, 7, 9, 10: $S / L$ heterozygotes; lanes 4, 5, 8: hsr-omega homozygotes. (d) Southern blot of hybrid lines. Lanes 1-5: L1-L5 lines, respectively, lanes 6-10: S1-S5 lines, respectively.

an 8 bp indel polymorphism (Figure $2 \mathrm{a}, \mathrm{c}$ ). The insertionbearing allele, L, occurred within chromosome sequences that encoded hsr-omega ${ }^{a}$ (McKechnie et al, 1998). We refer to the indel variants as the hsr-omega long (hsr-omega ${ }^{L}$ or L) and hsr-omega short (hsr-omegas or S) alleles, respectively, indicating the presence (L) or absence (S) of the indel. More distally, at a $3^{\prime}$ position in the gene, extensive variation in the number of tandem repeats occur. Some laboratory strains have as few as $5 \mathrm{~kb}$ of a $280 \mathrm{bp}$ repeat unit and others as many as $16 \mathrm{~kb}$ of these repeats (Hogan et al, 1995). We also detected the repeat-length variation at the $3^{\prime}$ end of the gene using Southern blots (Figure 2a, d).
To look for thermal phenotype differences associated with the chromosome 3 variation, we created a set of lines that were controlled for the chromosomal region tightly linked to the L/S variation but that had randomized genetic backgrounds for other genetic differences that occur between high and low latitude populations. We examined the set of five $\mathrm{L}$ and five $\mathrm{S}$ lines for the presence of $\operatorname{In}(3 R) P$ by crossing each line to a stock known to be homozygous for the standard chromosome 3 arrangement and cytologically inspected the F1 larval salivary gland squashes. Without exception the derivation process resulted in fixation of the $\mathrm{L}$ lines for the standard arrangement and fixation of the $S$ lines for the inverted arrangement. We also examined these 10 lines for the $3^{\prime}$ repeat-length variation of hsr-omega and found that the different sets were virtually fixed for different repeat-length alleles (Figure $2 \mathrm{~d}$ ). The $\mathrm{S}$ lines were each homogeneous for repeats totalling about $15 \mathrm{~kb}$ in length and the L lines for repeats with a total length of about $12 \mathrm{~kb}$ (except for one variable line that contained both 12 and $27 \mathrm{~kb}$ repeats). The data suggest that the original two north and south lines chosen for hybridization had been fixed for either the noninverted right arm of chromosome 3 (the southern $\mathrm{L}$ line) or the inverted $(\operatorname{In}(3 R) P)$ right arm of chromosome 3 (the northern $\mathrm{S}$ line). $\mathrm{L}$ and $\mathrm{S}$ have acted as markers for linked blocks of genes in this region of chromosome 3 . In this instance, $S$ marked both the presence of $\operatorname{In}(3 R) P$ and an allele of hsromega that contained about $15 \mathrm{~kb}$ of $3^{\prime}$ repeats and no $8 \mathrm{bp}$ indel at the L/S site.

Using a small-vial tolerance test, the hybrid lines and their parental strains were tested for heat resistance, both with and without a prior mild-heat hardening treatment. The relative heat resistance, for both unhardened and hardened flies, as measured by average knockdown time is depicted in Figure 3a. No significant difference between the parental strains was detected. However, a significant effect of genotype was indicated by nested ANOVA when the analysis was carried out on the 10 lines marked by $\mathrm{L}$ and $S\left(\mathrm{~F}_{1,8}=6.60, P<0.05\right)$, with the $\mathrm{L}$ lines being more heat susceptible than the $S$ lines (and no suggestion of any interactions). Effects of hardening $\left(\mathrm{F}_{1,8}=1.029 .2, P<0.001\right)$ and of line within genotype $\left(\mathrm{F}_{8,180}=3.81, P<0.001\right)$ were detected. A genotype by hardening interaction effect $\left(F_{2,12}=5.51, P<0.05\right)$ was detected when the five $\mathrm{H}$ lines, which were each polymorphic for the L/S markers, were included in the analysis. This was because of the $\mathrm{H}$ lines displaying a relatively high, unhardened heat resistance like $S$ lines, but a hardened heat resistance that was relatively low like the L lines. These data support the hypothesis that the chromosome 3 segment marked by the L/S variation is part of the genetics that underlies an individual's susceptibility to heat stress.

The different ways that an organism experiences thermal stress may challenge different physiological and genetic mechanisms. To examine the generality of any effect of this variation on heat resistance, a large-tube heat knockdown test was also carried out on batches of adults from four of the hybrid lines, two L lines and two $S$ lines, both with and without prior hardening. Relative knockdown times for nonhardened lines did not indicate a significant genotype, or line within genotype, effect. However, relative knockdown times for the heathardened lines indicated a significant difference between 
genotypes $\left(\mathrm{F}_{1,2}=55.33, P<0.05\right)$, with no effect of line (Figure 3b). This difference in sensitivity between hardened and nonhardened heat tolerance tests for detecting variation between $L$ and $S$ lines is consistent with previous results indicating that hsr-omega $a / b$ variation has a larger differential effect for hardened resistance (McColl et al, 1996). The L lines, carrying the chromosome 3 genotypes that occur at higher frequency in cool-temperate Australia, were also the more heat
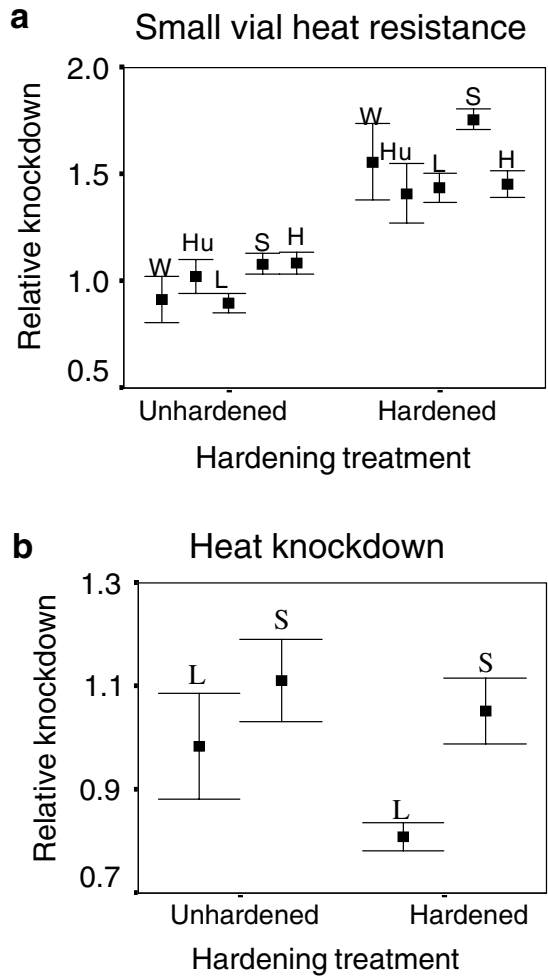

C

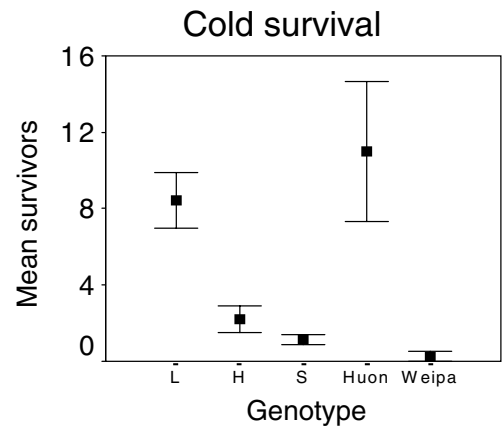

d

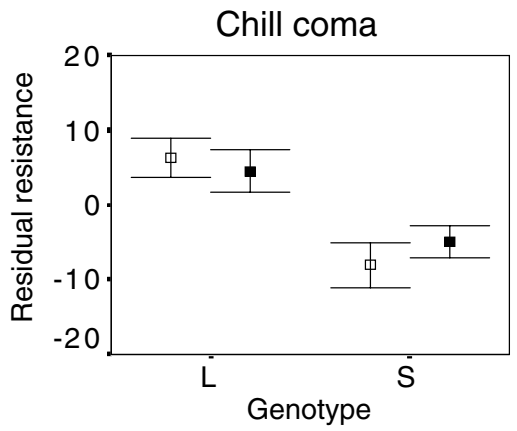

susceptible in this alternate test of heat stress, having shorter relative knockdown times after hardening than the $S$ lines. Thus, for two different measures of heatresistance $S$ lines outperformed L lines.

We also measured cold tolerance on the set of hybrid lines and their two parental strains using a mortality assay after a short exposure to $-2^{\circ} \mathrm{C}$. Significant variation occurred among genotypes $\left(\mathrm{F}_{2,14}=21.40\right.$, $P<0.001)$ with no effect of line within genotype. $L$ lines had a higher cold tolerance (Figure 3c), with a Tukey post hoc test indicating that only this genotype was clearly different to the $\mathrm{S}$ and $\mathrm{H}$ line groups. The parental line that originated from the southern cool-temperate region (that carried the L marker) clearly had a higher cold tolerance than the northern-derived parental line (that carried the $S$ marker). We also used a chill-coma recovery measure of cold tolerance to see if the hybrid-derived $\mathrm{L}$ lines were more cold tolerant than the $S$ lines in this different measure of cold sensitivity (Figure 3d). Again, the $\mathrm{L}$ lines were more resistant, recovering faster from the chill coma in both females $\left(\mathrm{F}_{1,121}=24.73, P<0.01\right)$ and males $\left(\mathrm{F}_{1,116}=5.70, P<0.05\right)$. The chromosome 3 element marked by $\mathrm{L}$ therefore provided elevated cold resistance over S-marked elements for two different types of cold stress. The data suggest that the alternate genetic elements fixed in the $S$ and $L$ lines each provide a positive boost to fitness under one type of thermal stress at the cost of conferring a negative fitness effect at the opposite temperature extreme.

We asked if the $h s r$-omega ${ }^{L / S}$ variation marked a region of chromosome 3 that varied clinally as did the previously reported $h s r$-omega $a^{a / b}$ variation. Frequency estimates of the $\mathrm{L}$ allele along a latitudinal transect of Australian east-coast sites (Figure 4a), all taken at low altitudes of $<200 \mathrm{~m}$, are plotted in Figure $4 \mathrm{~b}$ and indicate a positive association with latitude. This geographical L/ $S$ variation is spatially autocorrelated, since a Mantel difference-matrix comparison between all sites considered pairwise for $L$ allele frequency and linear distance indicated a highly significant association $(P<0.0001)$. Almost exactly the same level of association occurred if latitudinal differences are substituted for linear distance in the matrix comparison. Further, when population differences in L frequency are aligned with geographic separation distances in a partial Mantel test (Fortin and Gurevitch, 1993) that controls for latitudinal differences,

Figure 3 Thermal tolerance measurements. (a) Small-vial heat resistance of hardened and unhardened parental (W: Weipa, Hu: Huon) and hybrid lines (L: fixed for $h s r-o m e g a^{L}, \mathrm{H}$ : $50 \%$ each allele, S: fixed for $h s r$-omegas). $\mathbf{\square}$ : means based on 10 replicates for parental lines, 10 replicates for each of five lines for hybrid lines. Error bars represent standard error of the mean. (b) Large tube hardened and unhardened knockdown of two L lines and two S lines. $\mathbf{0}$ : mean relative knockdown when compared to a control line, based on three replicates. Error bars represent standard error of the mean. (c) Mean survival after exposure to $-2^{\circ} \mathrm{C}$ for $2 \mathrm{~h}$ of parental (Huon and Weipa) and hybrid (L, H, S) lines. - : mean number of flies surviving based on four replicates for each of five lines in the hybrid lines, and four replicates for parental lines. Error bars represent standard error of the mean. (d) Estimates of chill coma recovery after a treatment of $16 \mathrm{~h}$ at $0^{\circ} \mathrm{C}$. $\square$ : mean female residual recovery time based on measurements of 15 flies for each of four lines (S) and five lines (L). $\square$ : mean male residual recovery time based on measurements of 15 flies for each of four lines (S) and five lines (L). 


\section{a}
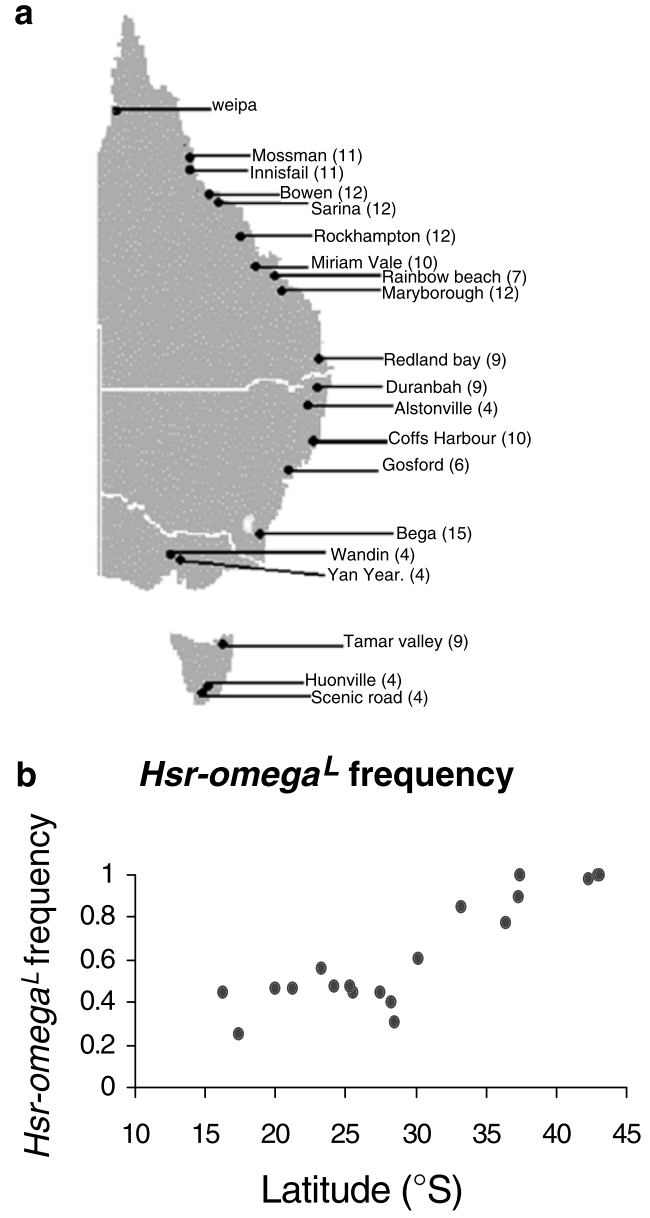

Figure 4 Clines. (a) Map of collection sites from the $3000 \mathrm{~km}$ transect on the eastern coast of Australia. Numbers in brackets represent number of isofemale lines genotyped for $h s r$-omega ${ }^{L / S}$ variation (Weipa excluded from latitudinal analyses). Latitudes of sites: Weipa $12.40^{\circ} \mathrm{S}$, Mossman $16.27^{\circ} \mathrm{S}$, Innisfail $17.32^{\circ} \mathrm{S}$, Bowen $20.01^{\circ} \mathrm{S}$, Sarina $21.25^{\circ} \mathrm{S}$, Rockhampton $23.22^{\circ} \mathrm{S}$, Miriam Vale $24.19^{\circ} \mathrm{S}$, Rainbow Beach $25.54^{\circ} \mathrm{S}$, Maryborough $25.31^{\circ} \mathrm{S}$, Redland Bay $27.39^{\circ} \mathrm{S}$, Duranbah $28.18^{\circ} \mathrm{S}$, Alstonville $28.5^{\circ} \mathrm{S}$, Coffs Harbour $30.19^{\circ} \mathrm{S}$, Gosford $33.25^{\circ} \mathrm{S}$, Bega $36.41^{\circ} \mathrm{S}$, Yan Yean $37.34^{\circ} \mathrm{S}$, Wandin $37.45^{\circ} \mathrm{S}$, Tamar Valley $42.24^{\circ} \mathrm{S}$, Huon $43.01^{\circ} \mathrm{S}$, Scenic Rd $43.03^{\circ} \mathrm{S}$. (b) Estimates of $h s$-omega $a^{L}$ frequency of 19 collection sites.

or aligned with latitudinal differences in a partial Mantel test that controls for separation distance, the significant associations are completely lost. Since the sample sites were chosen to lie along a near linear, north-south transect, these latitude and linear distance comparisons are behaving as one-and-the-same variable in the Mantel tests. The significant associations confirm the presence of a latitudinal/spatial cline in frequency of that region of chromosome 3 marked by the L allele among Australian east-coast populations, as previously indicated for the hsr-omega $a^{a / b}$ variation (McColl and McKechnie, 1999). If strong population disequilibrium occurs between the $\mathrm{L} / \mathrm{S}$ variation and $\operatorname{In}(3 R) P$, clinal variation of $\operatorname{In}(3 R) P$ could also underlie the clinal variation in this gene. Ongoing investigations should resolve these issues.

Using these latitudinal-transect data we examine L frequency associations with six climatic variables (temperature, rainfall and humidity statistics) in simple difference-matrix Mantel tests. Three of these, average maximum temperature for the hottest month, average minimum temperature for the coldest month and monthly rainfall for the wettest month, show significant associations (all $P<0.0001$ ). Since population differences for each of these three climatic variables are significantly associated with latitude differences (all $P<0.01$ ), partial Mantel tests that controlled for latitude were undertaken. Only one of these, the partial Mantel test for maximum temperature differences, retained a significant association with $\mathrm{L}$ differences $(P<0.01)$. The association between $\mathrm{L}$ and latitude differences is completely removed $(P=0.12)$ in the partial Mantel test that controls for maximum temperature. Therefore, the $\mathrm{L}$ frequency differences between populations are robustly associated with population differences in maximum temperature in the hottest month, but not with latitude or with the other climatic variables. These data support the hypothesis that environmental temperature directly or indirectly acts as a proximate selective factor for the region of chromosome 3 marked by the L/S variation.

\section{Discussion}

Our field collection suggests that we have identified in D. melanogaster a major genetic element that occurs at high frequency in tropical populations from coastal eastern Australia and decreases in frequency at higher latitudes, being replaced clinally by the alternate element. The tolerance data support the idea that the element can have substantial effects on both heat and cold tolerance. These results are consistent with earlier data indicating that allelic variation of hsr-omega can underlie heat-tolerance variation (McKechnie et al, 1998). They are also consistent with an earlier study indicating that cold-tolerance variation in both adult and larval $D$. melanogaster is largely attributable to a chromosome 3 effect (Tucic, 1979).

What is the nature of the element marked by hsr-omega L/S? It seems likely that for our hybrid line data this element is the common cosmopolitan inversion $\operatorname{In}(3 R) P$, a large inversion covering about six major cytological units and therefore about $6 \%$ of the genome (perhaps 1000 genes). In an earlier study, the frequency of $\operatorname{In}(3 R) P$ varied clinally in Australia, along almost the same east coast transect, being present at frequencies up to $60 \%$ in the north and almost absent in temperate populations (Knibb, 1982). The frequency of $\operatorname{In}(3 R) P$ has been associated with latitude in several other continents, along with the other common cosmopolitan inversions (Knibb, 1982). What factors other than thermal tolerance may influence the $\operatorname{In}(3 R) P$ cline? $\operatorname{In}(3 R) P$ has also been postulated to be at a disadvantage at high latitudes because it is associated with reduced flight ability under cooler conditions, possibly related to decreased body size (Stalker, 1980). Body size increases with latitude (Partridge et al, 1999) and two microsatellite markers that associate with latitude and map within $\operatorname{In}(3 R) \mathrm{P}$ (Gockel et al, 2001) have also been related to body size in a QTL study (Gockel et al, 2002). Clearly, some fine disecction of variable clinal markers and trait associations in this chromosomal region is required to tease apart the chromosomal regions and selective processes at work. However, if the $\operatorname{In}(3 R) P$ cline is still present in Australia, which seems likely, it may be this element that contributes to the opposing clines in tolerance to both temperature extremes (Hoffmann et al, 2002). 
While an effect of inversions is to maintain coadapted blocks of genes that are inherited as a group (Lewontin, 1974; Krimbas and Powell, 1992), recombination at reduced frequency occurs for the common inversions and linkage disequilibrium is not always strong, especially for polymorphic sites centrally placed in the inversion (Hasson and Eanes, 1996; Andolfatto and Kreitman, 2000; Verrelli and Eanes, 2000). A number of single gene polymorphisms in Drosophila, that lie within or in close proximity to inversions, have shown various levels of population disequilibrium with the inversion, yet display independent clinal variation or climatic associations (Knibb, 1983; Van't Land et al, 2000). Thus, the genetic element responsible for these temperature tolerance effects might be smaller than that covered by In(3R)P. A group of tightly linked genes surrounding the hsr-omega alleles that were isolated in these lines could be the causal elements. If a genetic element smaller than the inversion were to underlie the $L / S$ tolerance associations, we still need to be aware that these fitness associations might not be typical of all hsr-omega $\mathrm{L}$ and $S$ alleles, given that our crosses started with two isofemale lines. Likewise, our data does not exclude the possibility that other $\operatorname{In}(3 R) P$ chromosomes fail to show these thermal tolerance effects. Nonetheless, our data indicate that large thermal tolerance fitness effects, with potential to be ecologically relevant, are caused by a genetic element marked by hsr-omega L/S variation.

What are the candidate genes on the right arm of chromosome 3 that causally affect thermal tolerance and may be part of a coadapted genetic element? Four obvious candidates are hsr-omega, hsp68, dca and frost. Frost and Dca are two genes that are upregulated by cold treatment and map to chromosome 3R at $85 \mathrm{E} 2$ and $88 \mathrm{D}$, respectively (Goto, 2000, 2001) (Figure 1). Of these four genes, the expression patterns and potential phenotype affects for hsr-omega are the best understood. The evidence is now substantial that allelic variation in hsr-omega underlies a significant fraction of the heat sensitivity variation in D. melanogaster (McColl et al, 1996; McKechnie et al, 1998). Hsr-omega is both constitutively expressed in most tissues and upregulated by environmental factors. The relative and total levels of two major hsr-omega RNA transcripts are labile and fast to change in response to many environmental signals. The gene is thought to play a role in the dynamic coordination of nuclear and cytoplasmic transcript processing under various stress and growth conditions (Garbe et al, 1989; Pardue et al, 1990; Lakhotia et al, 1999; Lakhotia et al, 2001). However, we need to be cautious about assigning any genotype effect on thermal sensitivity directly to the differential function of hsr-omega alleles. If thermal selection in the field is responsible for the hsr-omega ${ }^{L}$ cline, the target of such selection may be groups of genes in linkage disequilibrium with hsr-omega variation. Transgenic studies with molecular constructs of hsromega that vary only at the relevant polymorphic sites are required to provide unambiguous evidence of effects of any single gene on these thermal fitness components.

In summary, our data suggest that polymorphic variation of hsr-omega is a marker for a genetic element on the right arm of chromosome 3, quite possibly $\operatorname{In}(3 R) P$, that provides insight into the genetics of adaptation to thermal extremes in a species that is widespread across diverse climatic regions. Variation of this element, at least in part, explains the known opposing thermal tolerance clines that occur along the eastern coast of Australia. The element found at high frequency in the tropics provides high adult heat tolerance at this end of the cline but incurs a trade-off in also causing cold sensitivity. The element is clinally replaced in cool-temperate southern populations by an alternate element with reciprocal effects. Such clinal polymorphic variation may help the species have a broad climatic range and be a thermal specialist at each end of the range where perhaps only one thermal extreme is regularly encountered; each element, in the right climate, may provide the appropriate thermal resistance benefits with little cost. Limited gene flow along the transect could serve to smooth any 'bumps' in the cline if thermal selection-intensity thresholds happen to change abruptly over space. Also, the polymorphism at any particular latitude might provide seasonal population flexibility where temperature extremes in one generation are interspersed with the opposite extreme several generations later. In this simplistic model, the fitness trade-offs would facilitate selection that leads to seasonal changes in frequency, as has been reported for $\operatorname{In}(3 R) P$ (Stalker, 1980). These data represent one of the few cases where opposing clinal selection on alternative genetic elements has been demonstrated and linked to geographic patterns and adaptive phenotypes.

\section{Acknowledgements}

We acknowledge the support of the Australian Research Council via their Special Research Centre Programme. Thanks to Erica Crone and Gawain McColl for help with assay development and use of figures, and to Michele Schiffer for the field collection effort.

\section{References}

Andolfatto P, Kreitman M (2000). Molecular variation at the In(2L)t proximal breakpoint site in natural populations of Drosophila melanogaster and D. simulans. Genetics 154: 1681-1691.

Azevedo RBR, French V, Partridge L (1996). Thermal evolution of egg size in Drosophila melanogaster. Evolution 50: 2338-2345.

Burton V, Herschel KM, Young P, Petersen NS (1988). Heat shock protection against cold stress in Drosophila melanogaster. Mol Cell Biol 8: 3550-3552.

Chen CP, Denlinger DL, Lee RE (1987). Cold shock injury and rapid cold-hardening in the flesh fly Sarcophaga crassipalpus. Physiol Zool 60: 297-304

Duncker BP, Chen C, Davies PL, Walker VK (1995). Antifreeze protein does not confer cold tolerance to transgenic Drosophila melanogaster. Cryobiology 32: 521-527.

Feder ME, Hofmann GE (1999). Heat-shock proteins, molecular chaperones, and the stress response: evolutionary and ecological physiology. Ann. Rev. Physiol. 61: 243-282.

Fortin MJ, Gurevitch J (1993). Mantel tests: spatial structure in field experiments, In: Scheiner M, Gurevitch J (eds) Design and Analysis of Ecological Experiments, Chapman \& Hall: London, pp 342-359.

Garbe JC, Bendena WG, Alfano M, Pardue ML (1989). A Drosophila heat shock locus with a rapidly diverging sequence but a conserved structure. J Biol Chem 261: 16889-16894

Gibert P, Moreteau B, Petavy G, Karan D, David JR (2001). Chill coma tolerance, a major climatic adaptation among Drosophila species. Evolution 55: 1063-1068. 
Gockel J, Kennington WJ, Hoffmann A, Goldstein DB, Partridge L (2001). Nonclinality of molecular variation implicates selection in maintaining a morphological cline of Drosophila melanogaster. Genetics 158: 319-323.

Gockel J, Robinson SJW, Kennington WJ, Goldstein DB, Partridge L (2002). Quantitative genetic analysis of natural variation in body size in Drosophila. Heredity 89: 145-153.

Goto SG (2000). Expression of Drosophila homologue of senescence marker protein-30 during cold acclimation. I Insect Physiol 44: 1111-1120.

Goto SG (2001). A novel gene that is up-regulated during recovery from cold shock in Drosophila melanogaster. Gene 270: 259-264.

Guerra D, Cavicchi S, Krebs RA, Loeschcke V (1997). Resistance to heat and cold stress in Drosophila melanogaster: inter and intra-population variation in relation to climate. Genet Selection Evol 29: 497-510.

Guy CL, G P-V, Brambl R (1986). Heat shock protects germinating conidiospores of Neurospora crassa against freezing injury. J Bacteriol 167: 124-129.

Hasson E, Eanes WF (1996). Contrasting histories of three gene regions associated with In(3L)Payne of Drosophila melanogaster. Genetics 144: 1565-1575.

Hoffmann AA, Anderson A, Hallas R (2002). Opposing clines for high and low temperature resistance in Drosophila melanogaster. Ecol Lett 5: 614-618.

Hoffmann AA, Dagher H, Hercus M, Berrigan D (1997). Comparing different measures of heat resistance in selected lines of Drosophila melanogaster. J Insect Physiol 43: 393-405.

Hoffmann AA, Parsons PA (1993). Selection for adult desiccation resistance in Drosophila melanogaster: fitness components, larval resistance and stress correlations. Biol. J. Linn Soc 48: 43-54.

Hogan NC, Slot F, Traverse KL, Garbe JC, Bendena WG, Pardue ML (1995). Stability of the tandem repeats in the Drosophila melanogaster hsr-omega nuclear RNA. Genetics 139: 1611-1621.

Huey RB, Kingsolver JG (1993). Evolution of resistance to high temperature in ectotherms. Am Nat 142: S21-S46.

Inoue Y, Watanabe T, Watanabe TK (1994). Evolutionary change of the chromosomal polymorphism in Drosophila melanogaster populations. Evolution 38: 753-765.

Jenkins NL, Hoffmann AA (1994). Genetic and maternal variation for heat resistance in Drosophila from the field. Genetics 137: 783-789.

Kimura MT (1988). Adaptation to temperate climates and evolution of overwintering strategies in the Drosophila melanogaster species group. Evolution 42: 1288-1297.

Knibb WR (1982). Chromosome inversion polymorphisms in Drosophila melanogaster: 2. Geographic clines and climatic associations in Australasia, North America and Asia. SO Genetica (Dordrecht) 58: 213-222.

Knibb WR (1983). Chromosome inversion polymorphisms in Drosophila melanogaster: 3. Gametic disequilibria and the contributions of inversion clines to the Adh and Gpdh clines in Australasia. SO - Genetica (Dordrecht) 61: 139-146.

Knibb WR, Oakeshott JG, Gibson JB (1981). Chromosome inversion polymorphisms in Drosophila melanogaster. II. Geographic clines and climatic associations in Australasia North America and Asia. Genetica. 58: 213-221.

Krebs RA, Loeschcke V (1995). Resistance to thermal stress in preadult Drosophila buzzatii: variation among populations and changes in relative resistance across life stages. Biol J Linn Soc 52: 517-531.

Krimbas CB, Powell JR (1992). Drosophila Inversions Polymorphism. CRC Press: Cleveland.

Lakhotia SC, Pritha R, Rajendra TK, Prasanth KV (1999). The non-coding transcripts of hsr-omega in Drosophila: do they regulate traffiking and availability of nuclear RNA-processing factors? Curr Sci 77: 553-563.
Lakhotia SC, Rajendra TK, Prasanth KV (2001). Developmental regulation and complex organisation of the promoter of the non-coding hsr-omega gene of Drosophila melanogaster. J Biol Sci 26: 25-38.

Lakhotia SC, Singh AK (1985). Non-Inducibilty of the 93D heatshock puff in cold reared larvae of Drosophila melanogaster. Chromosoma. 92: 48-54.

Lewontin RC (1974). The Genetic Basis of Evolutionary Change. Columbia University Press: New York.

McColl G, Hoffmann AA, McKechnie SW (1996). Response of two heat shock genes to selection for knockdown heat resistance in Drosophila melanogaster. Genetics 143: 1615-1627.

McColl G, McKechnie SW (1999). The Drosophila heat shock hsromega gene: An allele frequency cline detected by quantitative PCR. Mol Biol Evol 16: 1568-1574.

McKechnie SW, Halford MM, McColl G, Hoffmann AA (1998). Both allelic variation and expression of nuclear and cytoplasmic transcripts of hsr-omega are closely associated with thermal phenotype in Drosophila. Proc Natl Acad Sci USA 95: 2423-2428

Mettler JA, Voelker AA, Mukai T (1977). Inversion clines in populations of Drosophila melanogaster. Genetics 87: 169-176.

Mitrovski P, Hoffmann AA (2001). Postponed reproduction as an adaptation to winter conditions in Drosophila melanogaster: evidence for clinal variation under semi-natural conditions. Proc R Soc London B 268: 1-6.

Oakeshott JG, McKechnie SW, Chambers GK (1984). Population genetics of the metabolically related $A d h, G p d h$ and Tpi polymorphisms in Drosophila melanogaster I. Geographic variation in $G p d h$ and Tpi allele frequencies on different continents. Genetica 63: 21-29.

Ohtsu T, Kimura T, Katagiri C (1998). How Drosophila species acquire cold tolerance. Qualitative changes of phospholipids. Eur I Biochem 252: 608-611.

Pardue ML, Bendena WG, Fini ME, Garbe JC, Hogan NC, Traverse KL (1990). Hsr-omega, a novel gene encoded by a Drosophila heat shock puff. Biol Bull 179: 77-86.

Parsons PA (1977). Resistance to cold temperature stress in populations of Drosophila melanogaster and D. simulans. Austral J Zool 25: 693-698.

Partridge L, Langelan R, Fowler K, Zwaan B, French V (1999). Correlated responses to selection on body size in Drosophila melanogaster. Genet Res 74: 43-54.

Raymond M, Rousset F (1995). GENEPOP (version 1.2): population genetics software for exact tests and ecumenicism. J Heredity 86: 248-249.

Saiki RK, Gelfand DH, Stoffel S, Scharf SJ, Higuchi R, Horn GT et al (1987). Primer-directed enzymatic amplification of DNA with a thermostable DNA polymerase. Science 239: 487-491.

Singh AK, Lakhotia SC (1984). Lack of effects of microtubule poisons on the 93D or 93D-like heat shock puffs in Drosophila. Indian J Exp Biol 22: 569-576.

Stalker HD (1980). Chromosome studies in wild populations of Drosophila melanogaster: 2. Relationship of inversion frequencies to latitude, season, wing-loading and flight activity. Genetics 95: 211-224.

Tucic N (1979). Genetic capacity for adaptation to cold resistance at different developmental stages in Drosophila melanogaster. Evolution 33: 350-358.

Van't Land J, Van PWF, Villarroel H, Kamping A, Van DW (2000). Latitudinal variation for two enzyme loci and an inversion polymorphism in Drosophila melanogaster from Central and South America. Evolution 54: 201-209.

Verrelli BC, Eanes WF (2000). Extensive amino acid polymorphism at the Pgm locus is consistent with adaptive protein evolution in Drosophila melanogaster. Genetics 156: 1737-1752.

Yoon JS, Richardson RH, Wheeler MR (1973). A technique for improving salivery chromosome preparations. Experientia 29: 639-641. 